JOURNAL OF SYNCHROTRON RADIATION

ISSN 1600-5775

Received 30 January 2020

Accepted 21 July 2020

Edited by S. M. Heald, Argonne National Laboratory, USA

Keywords: radiation damage; soft X-rays; freeze-dried brain tissue; FTIR microscopy; $\mathrm{X}$-ray microscopy; radiation damage; soft X-rays; freeze-dried brain tissue.

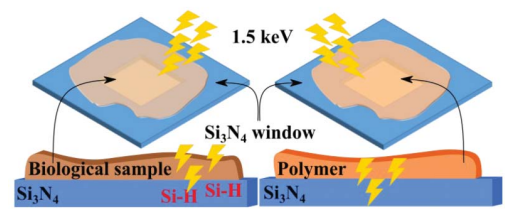

C 2020 International Union of Crystallography

\section{Soft X-ray induced radiation damage in thin freeze- dried brain samples studied by FTIR microscopy}

\author{
Artur D. Surowka, ${ }^{\mathrm{a}, \mathrm{b} *}$ A. Gianoncelli, ${ }^{\mathrm{a}}$ G. Birarda, ${ }^{\mathrm{a}}$ S. Sala, ${ }^{\mathrm{a}}$ N. Cefarin, ${ }^{\mathrm{a}, \mathrm{c}}$ \\ A. Matruglio, ${ }^{d}$ M. Szczerbowska-Boruchowska, ${ }^{b}$ A. Ziomber-Lisiak ${ }^{e}$ and L. Vaccari ${ }^{a}$ \\ ${ }^{\mathbf{a}}$ Elettra-Sincrotrone Trieste SCpA, SS 14, km 163.5, Basovizza, TS 34149 Trieste, Italy, ${ }^{\mathbf{b}}$ AGH University of Science \\ and Technology, Faculty of Physics and Applied Computer Science, al. Mickiewicza 30, Krakow 30-059, \\ Poland, 'IOM-CNR Laboratorio TASC, c/o Area Science Park, Basovizza, Trieste, Italy, d Department of Chemical \\ Engineering, University College London, London, United Kingdom, and ${ }^{\mathbf{e}}$ Chair of Pathophysiology, Faculty of Medicine, \\ Jagiellonian University, ul. Czysta 18, Kraków 31-121, Poland. *Correspondence e-mail: asurowka@agh.edu.pl
}

In order to push the spatial resolution limits to the nanoscale, synchrotron-based soft X-ray microscopy (XRM) experiments require higher radiation doses to be delivered to materials. Nevertheless, the associated radiation damage impacts on the integrity of delicate biological samples. Herein, the extent of soft X-ray radiation damage in popular thin freeze-dried brain tissue samples mounted onto $\mathrm{Si}_{3} \mathrm{~N}_{4}$ membranes, as highlighted by Fourier transform infrared microscopy (FTIR), is reported. The freeze-dried tissue samples were found to be affected by general degradation of the vibrational architecture, though these effects were weaker than those observed in paraffin-embedded and hydrated systems reported in the literature. In addition, weak, reversible and specific features of the tissue- $\mathrm{Si}_{3} \mathrm{~N}_{4}$ interaction could be identified for the first time upon routine soft X-ray exposures, further highlighting the complex interplay between the biological sample, its preparation protocol and X-ray probe.

\section{Introduction}

Unravelling the mechanistic link between metals, non-metals and molecular assemblies is essential for understanding the often contentious boundary between pathological and basal conditions in the brain (Collingwood \& Adams, 2017). Addressing this issue may facilitate identification of new biochemical markers that can accelerate the therapeutic development and improve diagnostics of the most common neurological disorders (Jellinger, 2010). It is therefore not surprising that there is a growing number of elementalcontrast micro-spectroscopic studies of brain samples (Pushie et al., 2018). Among them, synchrotron soft X-ray microscopy (XRM) has attracted interest due to the possibility for 2D mapping of biologically active low- $Z$ elements - C, N, O, Na and $\mathrm{Mg}$ - with a sensitive high-flux micro-probe (Gianoncelli et al., 2009). These elements deserve particular attention as a result of their involvement in a variety of neuro-physiological processes: neurotransmission, neurosynthesis, enzymatic activity and anti-oxidative mechanisms (Chellan \& Sadler, 2015; Bradshaw \& Smith, 2008; Kirkland et al., 2018). Combined synchrotron-based low-energy X-ray fluorescence (LEXRF) and scanning transmission soft X-ray microscopy (STXM) were found to be a powerful tool for simultaneous metal/non-metal sub-micrometre mapping together with detailed imaging of carbon-rich brain tissue structures (Duke et al., 2014). Specifically, complementary LEXRFSTXM studies have recently allowed for in situ studying of 
physiological mechanisms underlying brain energy metabolism, that is seen to be a critical factor for maintaining brain homeostasis (Surowka et al., 2019; Poitry-Yamate et al., 2013).

Although XRF microscopy offers the unprecedented possibility to investigate elemental distribution in a variety of (bio)samples, accumulated exposure to the microprobe can induce structural damage, and alter the elemental distribution (Jones et al., 2020). In particular, soft XRM experiments' versatility and suitability for brain tissue analysis rely on high absorption cross sections of $\mathrm{C}, \mathrm{N}$ and $\mathrm{O} K$-shells, especially in the so-called 'water window' (between $0.28 \mathrm{keV}$ and $0.54 \mathrm{keV}$ ), where the radiation is strongly absorbed by carbonrich biological structures (Teramoto et al., 2018). However, this impacts on the integrity of the biological material due to direct and indirect radiation damage pathways, in a manner that depends also on sample preparation. Sample preparation itself can induce chemical modifications that result in the biomolecules losing their native state. Direct damage events start nearly 1 ps to $1 \mathrm{fs}$ from the irradiation, thus resulting in ultrafast breakdown of $\mathrm{S}-\mathrm{H}, \mathrm{O}-\mathrm{H}, \mathrm{N}-\mathrm{H}$, and $\mathrm{C}-\mathrm{H}$ bonds (Reisz et al., 2014). Therefore, they may result in the loss of the native state of biomolecules. In the case of indirect damage, ionization of the solvent, mostly water, occurs, which can trigger (over-)production of free radicals that can break down chemical bonds and/or induce extensive oxidation of molecular assemblies (Weinhausen et al., 2014; Leccia et al., 2010). It is therefore possible to postulate that various post-irradiation biochemical events are expected in both hydrated and dried biological systems. This problem is now seen as a major limiting factor in high-resolution soft XRM, where substantially higher doses must be delivered for allowing nano-scale studies of cellular architecture (Bernhardt et al., 2016). One of the first studies in this matter by Beetz \& Jacobsen (2002) highlighted the impact of soft X-ray microprobe experiments on poly(methylmethacrylate) (PMMA) samples. The authors demonstrated that the $\mathrm{C}=\mathrm{O}$ bonds are particularly vulnerable targets to X-ray radiation damage during routine soft X-ray STXM experiments. More recently, Kosior et al. $(2012 a, b)$ presented a novel multimodal nanoscale approach to study the impact of a hard X-ray microprobe $(17 \mathrm{keV})$ on mass density and elemental concentrations of lyophilized P12 cells. Specifically, synchrotron-radiation XRF (SRXRF), propagationbased X-ray phase contrast imaging (XPCI) and scanning transmission ion microscopy (STIM) were proposed (Kosior $e t$ $a l ., 2012 b$ ). The authors concluded that SRXRF, as the higher dose technique, induces severe cellular mass density reduction, as investigated by XPCI. At the same time, XPCI and STIM modalities were found to deliver substantially lower doses. These techniques were therefore proposed as nearly non-destructive reference tools for quantifying elemental concentrations and sample mass density, respectively, so that the source of the damage could be efficiently decoupled from its probe (Kosior et al., 2012b). Another more recent multimodal strategy was proposed by Gianoncelli et al. (2015) to study soft X-ray radiation damage in formalin-fixed eukaryotic cells. The authors grew the cells onto radio-resistant $\mathrm{Si}_{3} \mathrm{~N}_{4}$ substrates to disentangle the sample damage from that of the substrate. The samples were exposed to $1 \mathrm{keV}$ soft $\mathrm{X}$-ray radiation at various doses ranging from $10^{6}$ to $10^{9} \mathrm{~Gy}$. For assessing the molecular changes upon irradiation, measurements by synchrotron radiation (SR) Fourier transform infrared microscopy (SR-FTIRM) and atomic force microscopy (AFM) were proposed. It was shown that the $1 \mathrm{keV}$ radiation induced extensive oligomerization and disintegration of the overall vibrational pattern and, to a lesser extent, of cellular architecture (Gianoncelli et al., 2015). A somehow similar strategy was adopted by Bedolla et al. (2018) to analyze soft X-ray radiation damage upon LEXRF and STXM experiments in paraffin-embedded rat tissue samples. The samples were fixed with formalin, glutaraldehyde and Karnovsky, and were then mounted onto popular Ultralene films. With the aid of FTIR imaging, the authors demonstrated that paraffin and Ultralene undergo complex radiation damage due to their mutual interference (Bedolla et al., 2018).

In this study, we explored the radiation damage induced on freeze-dried brain samples, focusing on the interaction between sample and substrate, as proposed by Bedolla et al. (2018). To this aim, different types of organic samples other than dehydrated brain slides were also investigated: collagen films and polymer thin films. FTIR microscopy was used for in situ analysis of post-irradiation molecular burden in the samples. Molecular characteristics of the radiation damage were also probed in the time domain to assess for the damage ageing effects.

\section{Materials and methods}

\subsection{Sample description}

In this study, rat brain frontal cortex (FCx) samples were used. FCx is a blend of two major anatomo-histological brain components: the grey and, to a lesser extent, white matter. The former is protein-rich due to highly abundant neuron bodies, whereas the latter is high-lipid due to myelin-rich fibre tracts. FCx is particularly interesting for research on neuro-metabolic disorders, such as obesity, as it plays a role in maintaining proper motor control of the organism (Surowka et al., 2018).

\subsection{Tissue sample preparation}

For the experiments, brain samples were taken from six $(n=6)$ male Wistar rats, housed in the Department of Patophysiology, Jagiellonian University, Medical College, Krakow, Poland. Once the animals were sacrificed, the brain specimens were rapidly removed, frozen at $-80^{\circ} \mathrm{C}$ and cryo-sectioned (at $-20^{\circ} \mathrm{C}$ ) into $20 \mu \mathrm{m}$-thick slices using a cryomicrotome. Next, the brain frontal cortex areas were identified, cut out from the specimens using a scalpel, mounted onto $100 \mathrm{~nm}$-thick $\mathrm{Si}_{3} \mathrm{~N}_{4}$ membranes, and eventually freeze dried at $-80^{\circ} \mathrm{C}$ (overnight). The bioethical permission was obtained from the local ethical committee on animal testing at Jagiellonian University (No. 157/2013). More details on the animal husbandry, ethics and sample preparation can be found elsewhere (Ziomber et al., 2018). 


\subsection{Polymer film preparation}

Polyvinyl alcohol (PVA) film-coating solution, known as the Partall Coverall film (Rexco, USA), was first diluted in water (PVA: $\left.\mathrm{H}_{2} \mathrm{O}=1: 4\right)$. Then, the polymer was spin-coated onto a $\mathrm{Si}_{3} \mathrm{~N}_{4}$ membrane window at 1000 r.p.m. for $1 \mathrm{~min}$. At this point the samples were transferred onto a hot plate and baked for $2 \mathrm{~min}$ at $100^{\circ} \mathrm{C}$. In parallel, $1 \mu \mathrm{m}$ of PMMA 669.06 was spin coated onto another clean $\mathrm{Si}_{3} \mathrm{~N}_{4}$ membrane window at 1000 r.p.m. for $1 \mathrm{~min}$. All the aforementioned procedures were carried out at the FNF Facility of Nanofabrication at IOM-CNR, Trieste, Italy.

\subsection{Synchrotron soft X-ray microscopy measurements}

The samples were exposed to $1.5 \mathrm{keV}$ soft X-ray radiation at the TwinMic beamline at Elettra Sincrotrone Trieste (Trieste, Italy) (Gianoncelli et al., 2016). The TwinMic microscope was operated in scanning mode, where a zone plate optics focuses the beam on the sample plane. Either STXM or STXM combined with LEXRF modality experiments were used, with different acquisition times pixel by pixel in the raster scan, for delivering various radiation doses to the samples, as in Bedolla et al. (2018). The experimental chamber was operated in vacuum, at a pressure of $10^{-6} \mathrm{mbar}$ for avoiding strong absorption of low-energy $K_{\alpha}$ lines in air. The data were eventually normalized to the beam-flux and deadtime. At the time-point T0 [cf. Fig. 1(a)], taking advantage of high resolution (either $1 \mu \mathrm{m}$ or $600 \mathrm{~nm}$ ) and short acquisition times of $20 \mathrm{~ms}$ (low dose - LD), $200 \mathrm{~ms}$ (medium dose - MD) and $8 \mathrm{~s}$ (high dose - HD), the FCx areas were scanned such that a coarse low-dose scan (STXM only) provided overview areas up to $320 \mu \mathrm{m} \times 320 \mu \mathrm{m}$ (with $1 \mu \mathrm{m}$ beam). Next, a medium-dose scan of a more constrained sub-area up to $80 \mu \mathrm{m}$ $\times 160 \mu \mathrm{m}$ was performed. In the end, in the high-dose 'spec-
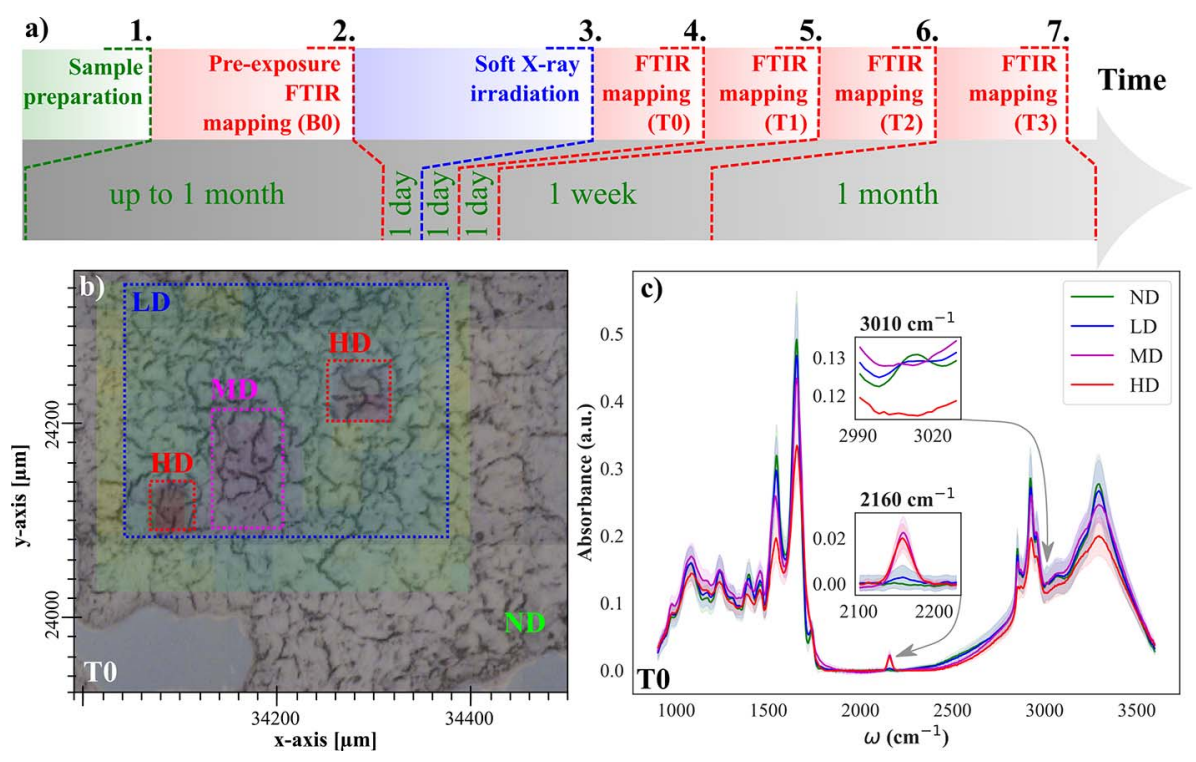

Figure 1

(a) Flowchart showing the sequence of experiments; (b) example irradiated tissue sample with LD-, MD- and HD-irradiated areas depicted; $(c)$ average, dose-dependent FTIR spectra acquired right after irradiation (the T0 time-stamp). trometry mode', small areas up to $40 \mu \mathrm{m} \times 40 \mu \mathrm{m}$ were mapped with the $600 \mathrm{~nm}$ beam size [as shown in Fig. 1(b)]. The pristine (PR) and no-dose (ND) areas were not irradiated. The low-, medium- and high-dose scanning yielded the cumulative doses/pixel of 6.7 MGy (LD, STXM only), 74 MGy (MD, STXM only) and 1700 MGy (HD, both STXM and LEXRF), as proposed by Gianoncelli et al. (2015).

\subsection{Fourier transform infrared (FTIR) microscopy experiments}

Radiation damage in the tissue- $\mathrm{Si}_{3} \mathrm{~N}_{4}$ samples was characterized by using benchtop FTIR mapping experiments at the Chemical and Life Science branch of the SISSI beamline at Elettra Sincrotrone Trieste (Trieste, Italy) (Lupi et al., 2007). For doing so, a Bruker Vertex 70v interferometer coupled to an IR microscope was used. The experiments were performed in transmission mode in the mid-IR (4000-900 $\mathrm{cm}^{-1}$ ) spectral range using a $15 \times$ objective/condenser. 128 and 256 scans were co-added for tissue and background acquisitions, respectively, and the spectral resolution was set to $4 \mathrm{~cm}^{-1}$. The resulting interferograms were apodized by the BlackmannHarris function. The FTIR data were recorded by a $\mathrm{LN}_{2}$ cooled mercury cadmium telluride (MCT) detector. The FCx samples were mapped with a knife-edge aperture constrained to $20 \mu \mathrm{m} \times 20 \mu \mathrm{m}$, whereas the scanned areas ranged from $80 \mu \mathrm{m} \times 80 \mu \mathrm{m}$ (scan of the damaged area) to $400 \mu \mathrm{m} \times$ $400 \mu \mathrm{m}$ (coarse overview scans). For each exposed sample, the FTIR mapping experiments were performed in four sessions at the following experimental time-points: the day before exposure (B0), right after (T0), the following day (T1), the following week (T2) and one month (T3) after an irradiation, as outlined in Fig. 1(a).

\subsection{FTIR imaging experiments}

Post-irradiation molecular changes in the 'model' samples (collagen- $\mathrm{Si}_{3} \mathrm{~N}_{4}$, collagen-SiC, PVA- $\mathrm{Si}_{3} \mathrm{~N}_{4}$, PMMA$\mathrm{Si}_{3} \mathrm{~N}_{4}$ and $\mathrm{Si}_{3} \mathrm{~N}_{4}$ systems) were characterized by using the benchtop FTIR imaging system at the Life Science and Chemical branch of the SISSI beamline. The samples were imaged with the $64 \times$ 64 pixel FPA detector, $15 \times$ objective/ condenser $(\sim 2.5 \mu \mathrm{m}$ effective pixel size) using the MIR glow-bar source. The spectral data were collected in the mid-IR (4000-900 $\mathrm{cm}^{-1}$ ) spectral range. 128 and 256 scans co-added for tissue/ polymer samples and background accumulations, respectively. The spectral resolution was set to $4 \mathrm{~cm}^{-1}$.

\subsection{Data processing for FTIR experiments}

The data were analyzed by in-house code written in Python 3.6 with its 
routine numpy, scipy and matplotlib packages (Van Der Walt et al., 2011; Hunter, 2007). Statistical significance of postirradiation molecular burden dynamics was quantified by repeated measure correlation analysis using a penguin package of Python (Vallat, 2018). Moreover, for removing the spectral fringing from the tissue- $\mathrm{Si}_{3} \mathrm{~N}_{4}$ spectra, the new Multiple Linear Regression Multi-Reference (MLR-MR) algorithm proposed by the authors was used with four average reference spectra indicative of ND-, LD-, MD- and HDexposed FTIR spectra. More details on processing the reference spectra as well as on correcting the raw data can be found elsewhere (Surowka et al., 2020).

\section{Results}

\subsection{Radiation damage in tissue- $-\mathrm{Si}_{3} \mathrm{~N}_{4}$ systems}

FTIR mapping experiments on brain tissues supported on $\mathrm{Si}_{3} \mathrm{~N}_{4}$ membranes were performed at five experimental timepoints: B0, T0, T1, T2 and T3, as outlined in Fig. 1(a). Fig. 1(c) shows average dose-dependent FTIR spectra of the irradiated tissue- $\mathrm{Si}_{3} \mathrm{~N}_{4}$ systems at the first time-point T0. Band area integrations of the $v(=\mathrm{CH}-)$ and $v(\mathrm{C}=\mathrm{O})_{\text {est }}$ versus exposure dose are shown in Table 1. Fig. 1(c) shows that the FTIR spectra were intact in the unexposed tissue areas (green solid line). At the same time, the LD (blue solid line), MD (magenta solid line) and HD (red solid line) areas were found with gradual, dose-dependent degradation of molecular moieties in C-O (1000-1100 $\left.\mathrm{cm}^{-1}\right)$, amide I-II $\left(1500-1700 \mathrm{~cm}^{-1}\right)$ and $\mathrm{CH}$-stretching $\left(2800-3000 \mathrm{~cm}^{-1}\right)$ spectral ranges. Upon the HD exposure, the majority of the tissue spectral features were still detectable, although they were found to be decreased by $\sim 30-50 \%$, as compared with the FTIR data of the pristine samples (PR, probed at B0). As expected, the band of unsaturated lipids $v(=\mathrm{CH}-)$ centred at $3010 \mathrm{~cm}^{-1}$ was no longer detectable already at the LD irradiation, thus these bonds were identified as the most fragile targets to soft X-rayinduced radiation damage, as it is known that these chemical moieties are prone to oxidation (Shahidi \& Zhong, 2010). This effect of double bond oxidation on lipids is also detectable in the $\mathrm{C}=\mathrm{O}$ band at $1730 \mathrm{~cm}^{-1}$. As the dose increases, this peak broadens and loses sharpness, becoming a shoulder of amide I at MD and HD. The signals from the other analyzed moieties such as hydroxyl $\left(-\mathrm{OH}, \sim 3431 \mathrm{~cm}^{-1}\right)$, aliphatic $\left(-\mathrm{CH}_{2}\right.$, $\left.\mathrm{CH}_{3}, \sim 2750-3000 \mathrm{~cm}^{-1}\right), \mathrm{C}-\mathrm{O}\left(\sim 1000-1100 \mathrm{~cm}^{-1}\right)$, phosphodiester $\left(-\mathrm{PO}_{4}{ }^{2-}, \sim 1230 \mathrm{~cm}^{-1}\right.$ and $1080 \mathrm{~cm}^{-1}$ ) bands [cf. Fig. 1(c)] were also reduced upon the MD irradiation, though still present in the spectra. In turn, the HD irradiation seemed to induce severe burden to molecular components in the irradiated areas. The peak maximum of amide I, due to protein backbone vibrations, underwent a slight red-shift towards $1650 \mathrm{~cm}^{-1}$. In addition, amide I-II bands were almost halved in the HD-exposed areas, as compared with the ND exposures. Similar remarks could be drawn for asymmetric and symmetric vibrational modes in methyl $\left(2959 \mathrm{~cm}^{-1}\right.$ and $\left.2870 \mathrm{~cm}^{-1}\right)$ and methylene $\left(2923 \mathrm{~cm}^{-1}\right.$ and $\left.2847 \mathrm{~cm}^{-1}\right)$ moieties in the LD, MD and HD areas.
Table 1

Dose-wise peak area integrations for $v(=\mathrm{CH}-), v(\mathrm{C}=\mathrm{O})_{\text {est }}$ and $v(\mathrm{Si}-\mathrm{H})$ spectral bands right after the exposure (T0).

Abbreviations: ND - no dose ( $c f$. Section 2.4); LD - low dose (cf. Section 2.4); MD - medium dose (cf. Section 2.4); HD - high dose ( $c f$. Section 2.4); $R_{\mathrm{s}}-$ Spaermann correlation coefficient; $p$ - significance value of the $R_{\mathrm{s}}$ coefficient.

\begin{tabular}{llll}
\hline & $v(\mathrm{Si}-\mathrm{H})\left(10^{-2}\right.$ a.u. $)$ & $v(\mathrm{C}=\mathrm{O})_{\text {est }}\left(10^{-2}\right.$ a.u. $)$ & $v(=\mathrm{CH}-)\left(10^{-3}\right.$ a.u. $)$ \\
\hline Dose/ & $R_{\mathrm{s}}=0.80$, & $R_{\mathrm{s}}=-0.73$, & $R_{\mathrm{s}}=-1.0$, \\
band & $p=0.20$ & $p=0.26$ & $p \ll 0.05$ \\
\hline PR & $<10^{-4}$ & $36.83 \pm 0.13$ & $28.7 \pm 1.7$ \\
ND & $<10^{-4}$ & $36.83 \pm 0.13$ & $26 \pm 11$ \\
LD & $\sim 10^{-2}$ & $25 \pm 11$ & $10.6 \pm 7.5$ \\
MD & $39 \pm 10$ & $<10^{-4}$ & $4.1 \pm 1.4$ \\
HD & $32.7 \pm 9.8$ & $<10^{-4}$ & $4.1 \pm 1.7$ \\
\hline
\end{tabular}

\subsection{Temporal characteristics of radiation damage in} tissue- $\mathrm{Si}_{3} \mathrm{~N}_{4}$ systems

Time- and dose-dependent average FTIR spectra for the tissue- $\mathrm{Si}_{3} \mathrm{~N}_{4}$ systems are shown in Fig. 2. In addition, the respective area integrations of $v(=\mathrm{CH}-), v(\mathrm{C}=\mathrm{O})_{\text {est }}$ bands are shown in Table 2, in relation to both radiation dose and post-irradiation time. As shown in Fig. 2, given a single dose group (ND, LD, MD, HD), the time-dependent average spectra were almost indistinguishable from each other, and all the spectral differences fell within one mean standard error interval. However, after carefully analyzing the data in Table 2 , it appears that all the $v(=\mathrm{CH}-), v(\mathrm{C}=\mathrm{O})_{\text {est }}$ peak area integrations for the LD-, MD- and HD-exposed areas were found with weak $\left(\left|r_{\mathrm{rm}}\right|<0.4\right)$, negative and highly significant $(p \ll 0.05)$ correlations with time. Also for the unexposed (ND) areas the olefinic $=\mathrm{CH}-$ stretch bands were found with weak $\left(r_{\mathrm{rm}}=-0.11\right)$ but significant $(p \ll 0.05)$ negative correlation with time, confirming that unsaturated lipids tend to oxidise when exposed to air, and that this phenomenon speeds up when the sample is exposed to X-rays as well. Interestingly, as can be seen in Fig. 1, and Figs. 2(b)-2(d), a single weak band at $2160 \mathrm{~cm}^{-1}$ appeared upon irradiation in the HD- and MD-exposed areas and, to a lesser extent, in LD tissue compartments ( $c f$. Table 2). From the literature, we assigned this band to $v(\mathrm{Si}-\mathrm{H})$ (Stryahilev et al., 2000). The intensity of this band was found to increase after the irradiation (T0), relative to the pristine sample (probed at B0). Its integrated peak intensity seemed to reach the maximum in the MD- and HD-exposed areas right after irradiation. As of the T1 time-stamp, the band's intensity was exponentially decreasing until $\mathrm{T} 3$ with a half time roughly estimated in five days.

\subsection{Radiation damage in $\mathrm{Si}_{3} \mathrm{~N}_{4}$ membranes}

In order to understand whether the observed local formation of these $\mathrm{Si}-\mathrm{H}$ bonds was mainly due to interaction of $\mathrm{Si}_{3} \mathrm{~N}_{4}$ with impurities, a single clean $\mathrm{Si}_{3} \mathrm{~N}_{4}$ membrane was irradiated with the HD. In Fig. 3(a), the average FTIR spectrum of the HD-exposed pure $\mathrm{Si}_{3} \mathrm{~N}_{4}$ membrane is shown in the $2050-2300 \mathrm{~cm}^{-1}$ spectral range. These data show that no spectral features could be distinguished from the baseline. 


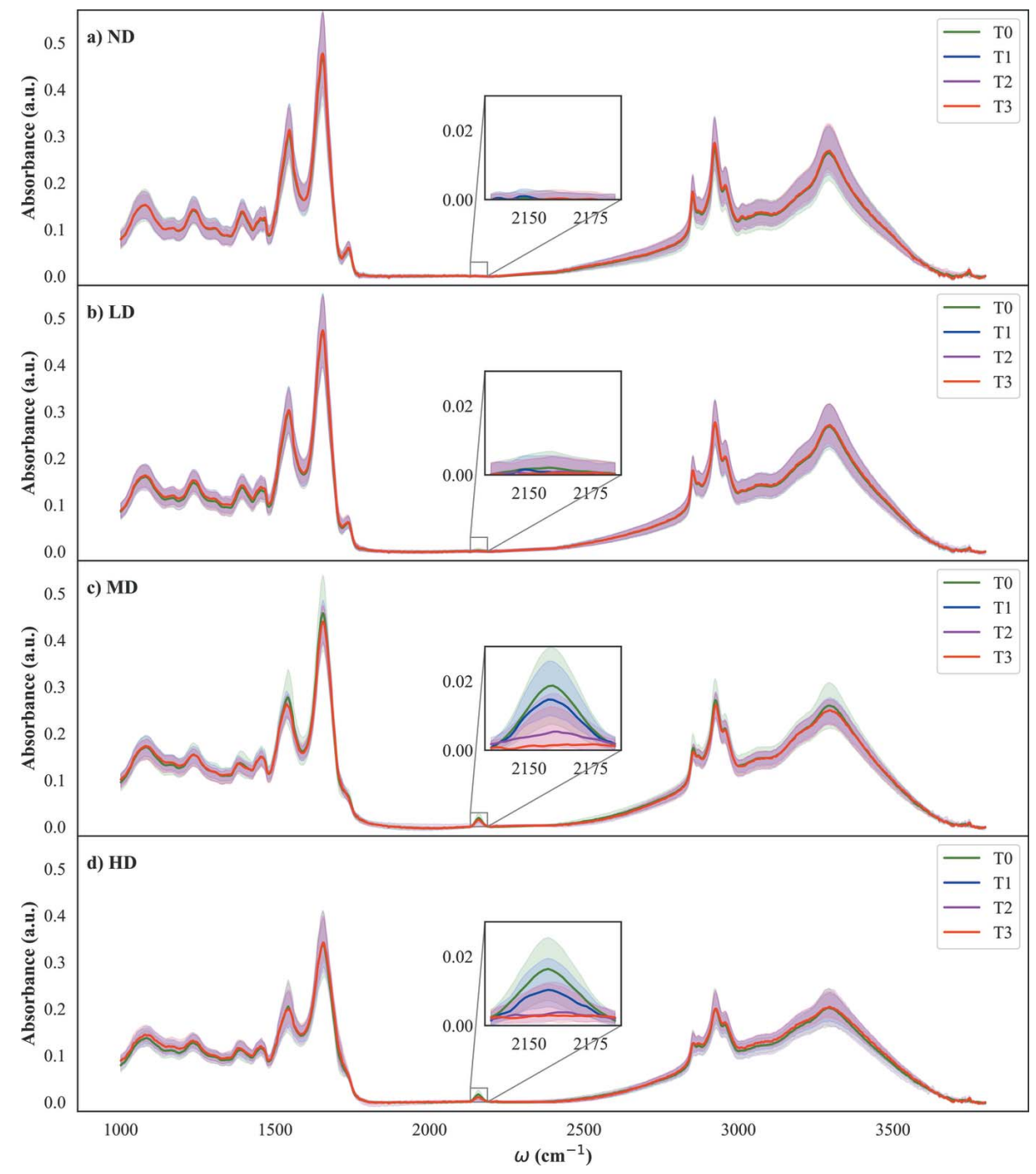

Figure 2

Average, dose- and time- (T0, T1, T2 and T3 timestamps) dependent FTIR spectra for: (a) ND; (b) LD; (c) MD and (d) HD exposures. The insets show the zoomed-in $\mathrm{Si}-\mathrm{H}$ band intensity spectra. Solid lines represent the mean, whereas the shadows show \pm SD.

These results lead us to design a further set of experiments in order to understand the mechanism underlying the local modification of the $\mathrm{Si}_{3} \mathrm{~N}_{4}$ membrane: whether it is due to the interaction of any exposed organic thin film with the $\mathrm{Si}_{3} \mathrm{~N}_{4}$ or whether it is specific to the presence of biomolecules (mainly proteins).

\subsection{Radiation damage in synthetic films}

To further investigate the origin of the $v(\mathrm{Si}-\mathrm{H})$ signal, if any exposed organic thin film can be involved in the generation of post-exposure $\mathrm{Si}-\mathrm{H}$ bonds in $\mathrm{Si}_{3} \mathrm{~N}_{4}$, a set of synthetic model films, spin-coated onto $\mathrm{Si}_{3} \mathrm{~N}_{4}$, were exposed to $\mathrm{LD}, \mathrm{MD}$ and HD soft X-ray radiation. This analysis allowed us to explore the different reactivity between the substrate and the samples (Tzvetkov et al., 2014; Beetz \& Jacobsen, 2003). The average dose-dependent FTIR spectra in Fig. 3 show that even the HD-irradiation did not produce any spectral signatures in the $2050-2300 \mathrm{~cm}^{-1}$ spectral range.

\section{Discussion}

\subsection{Radiation damage in protein films}

Seeing that no effective new signal was obtained for the aforementioned synthetic films, we investigated a protein film of collagen on both $\mathrm{Si}_{3} \mathrm{~N}_{4}$ (collagen- $\mathrm{Si}_{3} \mathrm{~N}_{4}$ ) and $\mathrm{SiC}$ (collagen$\mathrm{SiC})$ substrates. The samples were irradiated with HD and then analyzed by FTIR imaging in the HD areas at different times: right after, one day after, and two days after the exposure. Fig. 4(a) depicts time-wise transmission FTIR spectra of the HD-irradiated areas for the collagen- $\mathrm{Si}_{3} \mathrm{~N}_{4}$ system. These data show prominent spectral features of the $\mathrm{Si}-\mathrm{H}$ band that emerged right after the exposure. The same results were obtained for the collagen-SiC system ( $c f$. Fig. 5). The $\mathrm{Si}-\mathrm{H}$ chemical maps in Figs. 4 and 5 show that the $\mathrm{Si}-\mathrm{H}$ band perfectly colocalizes to the irradiated areas. Moreover, the $\mathrm{Si}-\mathrm{H}$ band was no longer detectable after three days from the irradiation [Fig. 4(c)] in the collagen$\mathrm{Si}_{3} \mathrm{~N}_{4}$ system. For the collagen-SiC system, it took nearly seven days for the $\mathrm{Si}-\mathrm{H}$ signal to vanish. It should be therefore highlighted that the dynamics of the $\mathrm{Si}-\mathrm{H}$ decay in the collagen$\mathrm{Si}_{3} \mathrm{~N}_{4}$ system was faster than that of the collagen-SiC one. Interestingly, in the collagen-SiC system, in addition to $\mathrm{Si}-\mathrm{H}$ bonding, a second weak spectral feature was also detected at $\sim 2250 \mathrm{~cm}^{-1}$, which was likely due to $\mathrm{Si}-\mathrm{N}=\mathrm{C}=\mathrm{O}$ bonding $[c f$. Fig. $4(b)$ and Fig. 5] (Launer \& Arkles, 2013).

The goal of this study, that was performed on diverse organic samples (freeze-dried brain tissue slices, polymeric and protein thin films) mounted onto soft X-ray compatible substrates $\left(\mathrm{Si}_{3} \mathrm{~N}_{4}\right.$ and $\left.\mathrm{Si}-\mathrm{C}\right)$, was twofold: (i) the characterization of dose-dependent molecular burden events displayed right after soft X-ray irradiation; (ii) the analysis of temporal characteristics of those events on the day, the week and the month after the exposure to the micro-probe.

Concerning the freeze-dried tissues, the samples were irradiated with the soft X-ray microprobe of three different dose-area characteristics: LD, MD and HD. It was demonstrated that all the soft X-ray exposures, regardless of the delivered dose, induced a loss in structure of the carbonyl ester $(\mathrm{C}=\mathrm{O})$ band of phospholipids and the reduction of olefinic $(=\mathrm{CH}-)$ bonds in polyunsaturated lipids ( $c f$. Figs. 1 and 2 and Tables 1 and 2). This suggests lipid oxidation and 
Table 2

Time-dependent peak area integrations of $v(\mathrm{Si}-\mathrm{H})$ (integration area: $\left.2120-2200 \mathrm{~cm}^{-1}\right) ; \quad \nu(\mathrm{C}=\mathrm{O})_{\text {est }} \quad$ (integration area: $1700-1730 \mathrm{~cm}^{-1}$ ), $v(=\mathrm{C}-\mathrm{H})$ (integration area: $3000-3020 \mathrm{~cm}^{-1}$ ) spectral ranges.

Abbreviations: ND - no dose ( $c f$. Section 2.4); LD - low dose (cf. Section 2.4); MD - medium dose (cf. Section 2.4); HD - high dose (cf. Section 2.4); $r_{\mathrm{rm}}-$ repeated measure correlation coefficient; $p$ - significance value of the $r_{\text {rm }}$ coefficient

\begin{tabular}{|c|c|c|c|c|}
\hline \multirow[b]{2}{*}{$\begin{array}{l}\text { Dose/ } \\
\text { day }\end{array}$} & \multicolumn{4}{|l|}{$v(\mathrm{Si}-\mathrm{H})$} \\
\hline & ND (a.u.) & $\begin{array}{l}\mathrm{LD}\left(10^{-2} \text { a.u. }\right) \\
r_{\mathrm{rm}}=-0.027 \\
p=0.047\end{array}$ & $\begin{array}{l}\mathrm{MD}\left(10^{-2} \text { a.u. }\right) \\
r_{\mathrm{rm}}=0.054 \\
p \ll 0.05\end{array}$ & $\begin{array}{l}\text { HD }\left(10^{-2} \text { a.u. }\right) \\
r_{\mathrm{rm}}=-0.097, \\
p \ll 0.05\end{array}$ \\
\hline B0 & $<10^{-4}$ & $<10^{-4}$ & $<10^{-4}$ & $<10^{-4}$ \\
\hline $\mathrm{T} 1$ & $<10^{-4}$ & $2.85 \pm 0.13$ & $29.8 \pm 2.3$ & $24.8 \pm 2.7$ \\
\hline $\mathrm{T} 2$ & $<10^{-4}$ & $2.24 \pm 0.14$ & $24.8 \pm 2.3$ & $14.1 \pm 1.7$ \\
\hline T3 & $<10^{-4}$ & $<10^{-4}$ & $5.32 \pm 0.44$ & $4.32 \pm 0.56$ \\
\hline \multirow[t]{2}{*}{$\mathrm{T} 4$} & $<10^{-4}$ & $<10^{-4}$ & $1.59 \pm 0.19$ & $2.42 \pm 0.34$ \\
\hline & \multicolumn{4}{|c|}{$v(\mathrm{C}=\mathrm{O})_{\text {est }}$ (a.u. $)$} \\
\hline $\begin{array}{l}\text { Dose/ } \\
\text { day }\end{array}$ & $\begin{array}{l}\text { ND }\left(10^{-2} \text { a.u. }\right) \\
r_{\mathrm{rm}}=-0.014 \\
p>0.28\end{array}$ & $\begin{array}{l}\mathrm{LD}\left(10^{-2} \text { a.u. }\right) \\
r_{\mathrm{rm}}=-0.19 \\
p \ll 0.05\end{array}$ & $\begin{array}{l}\text { MD }\left(10^{-2} \text { a.u. }\right) \\
r_{\mathrm{rm}}=-0.33 \\
p \ll 0.05\end{array}$ & $\begin{array}{l}\text { HD }\left(10^{-2} \text { a.u. }\right) \\
r_{\mathrm{rm}}=-0.22, \\
p \ll 0.05\end{array}$ \\
\hline B0 & $36.83 \pm 0.13$ & $36.83 \pm 0.13$ & $36.83 \pm 0.13$ & $36.83 \pm 0.13$ \\
\hline $\mathrm{T} 1$ & $34.22 \pm 0.34$ & $27.59 \pm 0.29$ & $7.3 \pm$ & $3.8 \pm 1.0$ \\
\hline $\mathrm{T} 2$ & $35.07 \pm 0.19$ & $27.91 \pm 0.26$ & $5.53 \pm 0.50$ & $5.2 \pm 1.3$ \\
\hline T3 & $34.97 \pm 0.14$ & $26.02 \pm 0.23$ & $3.75 \pm 0.38$ & $7.2 \pm 1.7$ \\
\hline \multirow[t]{2}{*}{$\mathrm{T} 4$} & $35.23 \pm 0.20$ & $27.15 \pm 0.23$ & $5.73 \pm 0.40$ & $6.8 \pm 1.3$ \\
\hline & \multicolumn{4}{|c|}{$v(=\mathrm{CH}-)$ (a.u. $)$} \\
\hline $\begin{array}{l}\text { Dose/ } \\
\text { day }\end{array}$ & $\begin{array}{l}\text { ND }\left(10^{-4} \text { a.u. }\right) \\
r_{\text {rm }}=-0.14 \\
p \ll 0.05\end{array}$ & $\begin{array}{l}\mathrm{LD}\left(10^{-4} \text { a.u. }\right) \\
r_{\mathrm{rm}}=-0.39 \\
p \ll 0.05\end{array}$ & $\begin{array}{l}\mathrm{MD}\left(10^{-4} \text { a.u. }\right) \\
r_{\mathrm{rm}}=-0.29 \\
p \ll 0.05\end{array}$ & $\begin{array}{l}\text { HD }\left(10^{-4} \text { a.u. }\right) \\
r_{\mathrm{rm}}=-0.20, \\
p \ll 0.05\end{array}$ \\
\hline B0 & $287.0 \pm 1.7$ & $287.0 \pm 1.7$ & $287.0 \pm 1.7$ & $287.0 \pm 1.7$ \\
\hline $\mathrm{T} 1$ & $286.3 \pm 1.7$ & $117.2 \pm 4.2$ & $37 \pm 12$ & $17 \pm 13$ \\
\hline $\mathrm{T} 2$ & $320.0 \pm 3.5$ & $120.0 \pm 4.0$ & $14.4 \pm 3.6$ & $<10^{-4}$ \\
\hline T3 & $275.1 \pm 2.6$ & $78.9 \pm 3.2$ & $3.5 \pm 1.6$ & $<10^{-4}$ \\
\hline $\mathrm{T} 4$ & $241.1 \pm 3.0$ & $66.3 \pm 2.7$ & $<10^{-4}$ & $<10^{-4}$ \\
\hline
\end{tabular}

saturation of the double bonds (Saeed et al., 2015). Low radioresilience of these bonds follows from their high chemical reactivity. The double chemical bonding has a higher chemical reactivity than a single one, due to the so-called $\pi$-electron. As a result, double chemical bonds are much more prone to free radical attack due to radiation-driven generation of reactive oxygen species, among others (Ravelli \& McSweeney, 2000). Beetz \& Jacobsen (2003) showed that the $\mathrm{C}=\mathrm{O}$ band is extremely fragile to soft- $X$-ray-induced radiation damage exposures higher than $18 \times 10^{6} \mathrm{~Gy}$, and that the decay rate is independent of the temperature, as it is similar in cryogenic conditions ( $\mathrm{LN}_{2}$ cooling) and at room temperature. To a lesser extent, other moieties were also affected, such as the amide I, that was halved in intensity and red-shifted. This is indicative of the fragmentation of the peptide linkage (Barth, 2007). Similar remarks could be drawn for aliphatic methyl and methylene groups $\left(2800-3000 \mathrm{~cm}^{-1}\right)$. Due to higher absorption cross sections of tissue's $\mathrm{C}, \mathrm{N}, \mathrm{O} K$-shells in the lowenergy regime, post-irradiation burden in a dried biological brain specimen is mostly driven by photoelectrons that induce dehydration, decarboxylation, decarbonylation, deamination, desulfuralization alongside desorption of volatile components:
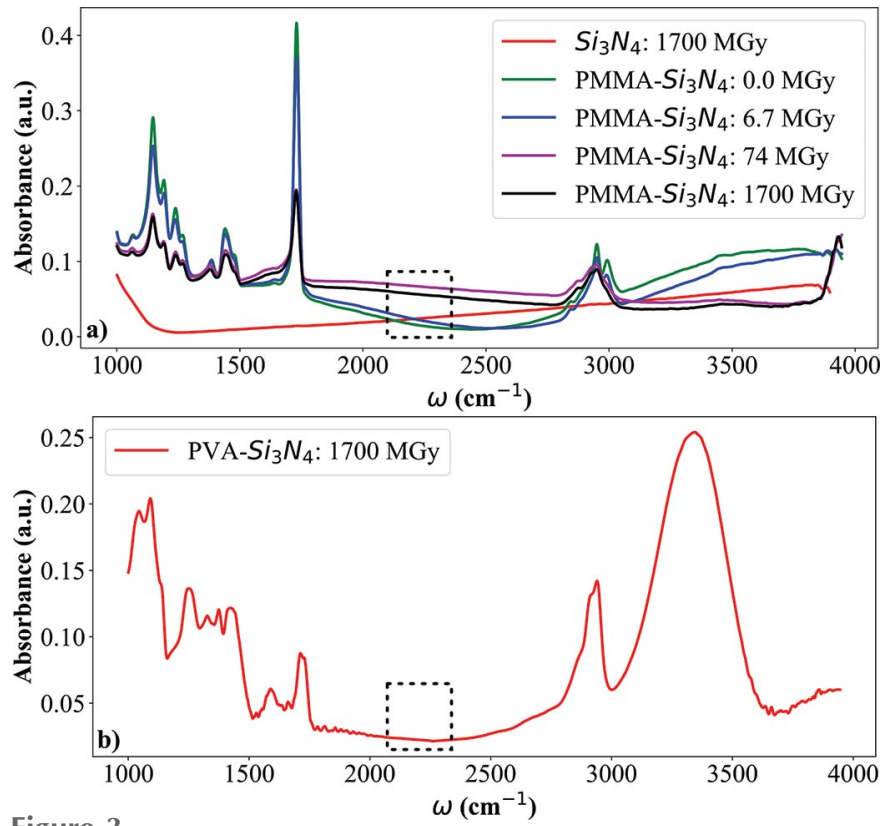

Figure 3

Average FTIR spectra for: (a) pure irradiated $\mathrm{Si}_{3} \mathrm{~N}_{4}$ (red solid line), nonirradiated PMMA-Si ${ }_{3} \mathrm{~N}_{4}$ (green solid line), LD-irradiated PMMA- $\mathrm{Si}_{3} \mathrm{~N}_{4}$ (blue solid line), MD-irradiated PMMA- $\mathrm{Si}_{3} \mathrm{~N}_{4}$ (magenta solid line), HDirradiated $\mathrm{PMMS}-\mathrm{Si}_{3} \mathrm{~N}_{4}$ (black solid line) systems; (b) HD-irradiated PVA- $\mathrm{Si}_{3} \mathrm{~N}_{4}$ (red solid line).

$\mathrm{H}_{2} \mathrm{O}, \mathrm{CO}_{2}, \mathrm{H}_{2} \mathrm{~S}, \mathrm{H}_{2}$ (Zubavichus et al., 2004). Gianoncelli et al. (2015) reported on the breakdown of covalent bonds in cellular lipids, proteins, carbohydrates, nucleic acids and phospholipids in formalin-fixed eukaryotic cells upon soft $\mathrm{X}$-ray exposures covering the dose range applied here. Herein, in line with Gianoncelli et al. (2015), the LD exposition
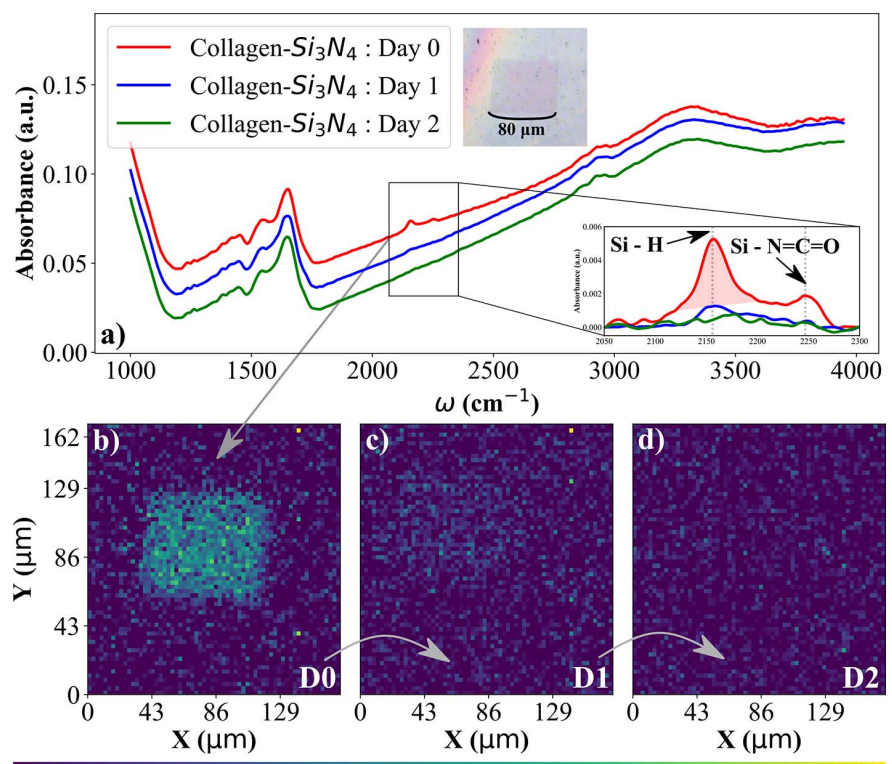

0.00

0.23

Figure 4

(a) Average, time-dependent FTIR spectra of the collagen- $\mathrm{Si}_{3} \mathrm{~N}_{4}$ system (the insets show the optical image of the sample and zoom-in of the 2050$2300 \mathrm{~cm}^{-1}$ spectral range); chemogram image for the integrated (2120$2200 \mathrm{~cm}^{-1}$ ) peak area of the $\mathrm{Si}-\mathrm{H}$ band: (b) right after; (c) day after; (d) two days after the HD irradiation. 


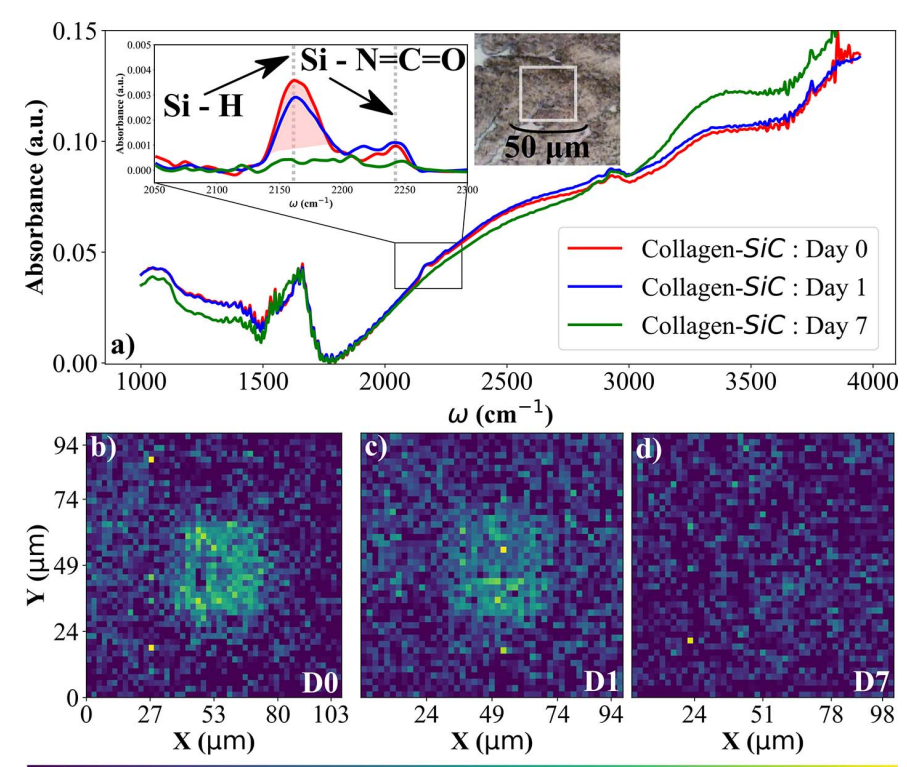

0.00

Figure 5

(a) Average, time-dependent FTIR spectra of the collagen-SiC system, truncated to the $2050-2300 \mathrm{~cm}^{-1}$ spectral range; chemogram image for the integrated $\left(2120-2200 \mathrm{~cm}^{-1}\right)$ peak area of the $\mathrm{Si}-\mathrm{H}$ band: $(b)$ right after; $(c)$ a day after; $(d)$ seven days after the HD irradiation.

induced $\sim 50 \%$ reduction of lipid ester bands, and nearly $60 \%$ decrease of double olefinic $(=\mathrm{CH}-$ ) ones ( $c f$. Table 1$)$. When it comes to MD and HD irradiation, herein and in Gianoncelli et al. we could observe complete suppression of the $\mathrm{C}=\mathrm{O}$ and $=\mathrm{CH}-$ signal right after the experiment, thus suggesting their comparable propensity to degradation in formalin-fixed cells and freeze-dried tissue sections (Gianoncelli et al., 2015). The only significant difference could be noted for other moieties such as aliphatic groups $\left(\sim 2750-3000 \mathrm{~cm}^{-1}\right)$, peptide bonds (amide I-II: $1500-1700 \mathrm{~cm}^{-1}$ ) and phosphodiester bonds (1000-1200 $\mathrm{cm}^{-1}$ ) upon the HD irradiation. Here, these bands were reduced by $10-20 \%$, though in Gianoncelli et al. they were no longer identified (Gianoncelli et al., 2015). Therefore, this remark implies that the HD irradiation may induce complete disintegration of the vibrational architecture in formallin-fixed cells, although in freeze-dried tissue systems we observe reduction of maximum absorbance by a decrement of $\sim 15-20 \%$. In line with this study, Bedolla et al. (2018) reported on similar effects: suppression of $=\mathrm{CH}-$ moieties and reduction of $\sim 20 \%$ maximum absorbance upon HD irradiation in soft X-ray-irradiated paraffin-embedded tissue slices. By comparing the recent studies by Gianoncelli et al. and Bedolla et al., one can infer that freeze-dried and paraffinembedded tissue sections are more radio-resistant - in terms of saturated aliphatic groups, peptide/oxydic/phosphodiester bonds - to soft X-ray radiation damage than formalin-fixed single cells, though the sensitivity of the $=\mathrm{CH}-$ moieties seems comparable, regardless of the sample type and preparation protocol.

The novelty of our investigation, compared with the studies by Gianoncelli et al. and Bedolla et al., is the detection of the spectral detail concerning the weak $\mathrm{Si}-\mathrm{H}$ band that here emerged right after tissue irradiation, proportionally to the dose. It was excluded that the $\mathrm{Si}_{3} \mathrm{~N}_{4}$ membrane itself could be implicated in the $\mathrm{Si}-\mathrm{H}$ bonding. Moreover, the involvement of surface aliphatic $\left(-\mathrm{CH}_{2}-,-\mathrm{CH}_{3}\right)$ moieties could also be disregarded, upon analyzing the post-exposure biochemical changes in the PMMA- $\mathrm{Si}_{3} \mathrm{~N}_{4}$ and $\mathrm{PVA}-\mathrm{Si}_{3} \mathrm{~N}_{4}$ systems studied here. However, the $\mathrm{Si}-\mathrm{H}$ bonding was again observed upon irradiation of the collagen- $\mathrm{Si}_{3} \mathrm{~N}_{4}$ and collagen- $\mathrm{SiC}$ samples, thus suggesting that the proteins' peptide bond may be implicated in this process. Johnson et al. (2011) reported that amides reveal a common pattern of photochemical bond breaking that spans the photon energy range between 11 and $600 \mathrm{eV}$. Specifically, it was demonstrated that the damage leaves a fingerprint at the $\mathrm{N} 1 s$ absorption edge, involving two low-lying $\pi^{*}$ transitions. Concerning the photochemical reactivity of $\mathrm{Si}_{3} \mathrm{~N}_{4}$ in the soft X-ray regime, very little information remains available at the moment. Gianoncelli et al. (2015) did not find any signs of $\mathrm{Si}_{3} \mathrm{~N}_{4}$ degradation/reactivity upon comparable soft X-ray exposures in formalin-fixed systems. It is therefore quite challenging to describe the radio-reactivity of $\mathrm{Si}_{3} \mathrm{~N}_{4}$ membranes observed here. In that respect there is, however, compelling evidence to show that the interaction of $1.5 \mathrm{keV}$ radiation with $\mathrm{N}$ may be due to photoelectric and Auger electrons. A fraction of their energy ( $\sim 20 \%)$ may lead to vibrational and electronic excitation of $\mathrm{N}$ species (herein $\mathrm{Si}_{3} \mathrm{~N}_{4}$, proteins and DNA), whereas the left out energy can induce subsequent ionization and formation of secondary electrons (Alizadeh et al., 2011). Note that it seems plausible that excited $\mathrm{N}$ species in the peptide bond can drive the postirradiation protonation in $\mathrm{Si}_{3} \mathrm{~N}_{4}$ and $\mathrm{SiC}$. Due to the substrates' high-degree purity, it seems possible that this is a protein-substrate interaction occurring at the interface. Interestingly, compared with the collagen- $\mathrm{Si}_{3} \mathrm{~N}_{4}$ systems, the observed $\mathrm{Si}-\mathrm{H}$ bonding was found to be more stable in the collagen-SiC system. This could be attributed to a higher attenuation coefficient and photoabsorption of soft X-rays for C in SiC (Hubbell \& Seltzer, 2004), thus yielding to its more extensive protonation. Interestingly, the $\mathrm{Si}-\mathrm{H}$ production is observed in dried samples only and seems to be absent in paraffin- and formalin-fixed sample matrices as reported by Gianoncelli et al. (2015) and Bedolla et al. (2018). It is difficult to find the exact explanation for this remark, though it is possible to hypothesize that paraffin in paraffin-embedded tissue samples can undergo an energy-deposition-driven phase transition towards the liquid phase (melting). Therefore, compared with dried samples, paraffin-embedded systems seem to be far more motile environments, thus allowing fast recombination of free radicals upon routine soft X-ray exposures. Another possible explanation is that the amount of biological material in the study by Gianoncelli et al. was just too low to see the formation of the $\mathrm{Si}-\mathrm{H}$ bond, given the fact that the maximum absorbance from a non-exposed cell was nearly five times lower than that observed in the tissue sections reported here. The height of the $\mathrm{Si}-\mathrm{H}$ band included less than $5 \%$ of the maximum absorbance, which would be at the noise level for the cellular systems reported by Gianoncelli et al. Needless to mention, the sample state plays an important role in radiation damage, and lyophilized samples have long 
been known to withstand radiation doses of the order of $10^{7}$ Gy (Williams et al., 1993). Single cells were, in turn, presented morphologically intact upon substantially higher doses up to $10^{10}$ Gy (Le Gros et al., 2016; Jones et al., 2017). Lombi et al. (2011) discovered that XRF micro-tomography experiments induce the dislocation of chemical elements in fresh apical tissue samples of cowpea. Specifically, in 3D reconstructions of $\mathrm{Zn} / \mathrm{Cu}$ concentration, the extent to signal loss was directly proportional to the delivered dose, starting from 0.18 MGy. Jones et al. (2017) reported on post-irradiation chemo-structural patterns in Caenorhabditis elegans samples of various preparation/hydration, all mapped by a hard XRF microprobe (15.6 keV energy). The authors concluded significant redistribution of labile ions of $\mathrm{K} / \mathrm{Ca}$. This was attributed to possible radiation-driven membrane rupture in the anaesthetized hydrated nematode species exposed to an X-ray dose higher than 1.5 MGy. At the same time, cryofixed and lyophilized specimens were found with higher tolerance doses up to $70 \mathrm{MGy}$ and $10 \mathrm{MGy}$, respectively. In the latter, however, the exposed region was identified with the stronger ultrastructural damage and shrinking, thus suggesting its higher radio-sensitivity than the cryofixed sample. Interestingly, in line with Bedolla et al (2018), Jones et al. (2017) reported that the sample's Ultralene film overlay was also damaged. Therefore, disentangling sample damage with that of the substrate is an additional challenge that must be tackled in order to provide a comprehensive overview of the interaction pattern in biological samples of different preparation protocols.

Regarding the temporal characteristics of radiation damage, almost no changes were noted up until one month after irradiation. The only significant trend was observed for the time evolution of the $\mathrm{Si}-\mathrm{H}$ band: it experienced a sharp increase upon the exposure, after which a nearly exponential decay was observed. This suggests that the post-irradiation $\mathrm{Si}_{3} \mathrm{~N}_{4}$ protonation is a reversible process that takes a maximum of one month for the $\mathrm{Si}_{3} \mathrm{~N}_{4}$ system to return to the initial state. Hence, although it was demonstrated that $\mathrm{Si}_{3} \mathrm{~N}_{4}$ cannot be considered inert to soft X-rays in $\mathrm{Si}_{3} \mathrm{~N}_{4}$-dried-tissue systems, its postexposure changes seem to be reversible. This proves overall radio-resilience of $\mathrm{Si}_{3} \mathrm{~N}_{4}$ in a nearly one-month time-scale upon routine soft XRM experiments. Temporal characteristics of radiation-driven sample degradation have been recently characterized by Jones et al. (2020) upon routine hard XRF microscopy measurements of fresh plant samples at the energy of $15.3 \mathrm{keV}$. Short-term effects involved substantial potassium (K) signal loss after $10 \mathrm{~min}$ upon $8.0 \mathrm{kGy}$ exposures. In our study, substantial sample blackening together with degradation of the organic matrix were observed right after $(\sim 20 \mathrm{~min})$ the LEXRF experiments ( $c f$. Fig. 1). Unfortunately, due to the current configuration of the vacuum-operated TwinMic setup, it is impossible to allow parallel/instant visual inspection of a sample during/right after the exposure, and the time-lag between measurement and inspection of 20 min cannot be avoided at the moment. Regarding long-term effects, Jones et al. demonstrated that radiation doses lower than 100 Gy do not induce any significant damage to thin specimens of roots and leaves up to nearly two weeks upon exposure. In the case of doses higher than $3.0 \mathrm{kGy}$, mild sample discoloration was noted on the second day upon the experiments. This was followed by substantial bleaching and browning nine days after the exposure. The most serious effects were noted for the $8.1 \mathrm{kGy}$ dose after two days, where severe blackening was observed due to cellulose carbonization by free radicals. Up from the fifth day, the K signal was no longer present, whereas $\mathrm{Ca}$ and $\mathrm{Mn}$ remained locked in place This suggests that radiation damage can impact time-wise concentration characteristics of highly diffusive elements in an irradiated hydrated sample (Jones et al., 2020). In this study, we were not able to observe such a pattern, since estimating elemental concentrations in the brain tissue is practically hindered by a strong observer effect in the soft X-ray regime (Hare et al., 2015). However, based on the observed FTIR spectra of the irradiated tissue areas, it could be concluded that a dried sample, itself, does not underlie any significant long-term degradation changes except for those involving the breakdown of the weak $\mathrm{Si}-\mathrm{H}$ bond, regardless of the dose.

Herein, we also quantified the observed molecular longterm radiation damage patterns by the repeated measure correlation analysis ( $c f$. Table 2). It could be found that the $v(=\mathrm{CH}-)$ moieties degraded with time in the ND areas. To a lesser extent, the lipid ester $\mathrm{C}=\mathrm{O}$ bands were also found to decay, though the time correlation was nearly zero and insignificant. This can be attributed to storage-related gradual olefinic oxidation, as reported by Stitt et al. (2012). From the data in Table 2, we could see that the LD, MD and HD irradiation had a stronger effect on the time-dependent degradation of the $v(=\mathrm{CH}-)$ moieties, as compared with $\mathrm{Si}-\mathrm{H}$ bonds. This itself is proof and evidence of increased propensity for ageing degradation effects. Recently, Jones et al. (2020) concluded that post-irradiation damage ageing effects involve bleaching, necrosis and carbonization of plant tissues. The authors highlighted long-term action of reactive free radicals. This can be a real struggle in dehydrated matrices, which seems to follow from radicals' substantially lower motility in dehydrated environments.

\section{Conclusions}

Our systematic investigation of the dose-dependent effects of the exposure to soft X-rays of diverse organic samples prepared on substrates compatible with XRM shows that radiation damage events in dried tissue- $-\mathrm{Si}_{3} \mathrm{~N}_{4}$ systems are different from those reported in the literature in paraffin-fixed samples. We demonstrated that the molecular arrangements undergone by the biological specimen, in particular by protein constituents, yield to the protonation of $\mathrm{Si}$ in $\mathrm{Si}-\mathrm{C}$ and $\mathrm{Si}_{3} \mathrm{~N}_{4}$, even though the last substrate was recently assumed to be radio-resistant for the same soft X-ray exposures. Overall, the presented results further confirm that radiation damage must be carefully addressed in XRM and XRF experiments, especially when soft X-rays and high radiation doses are delivered, and highlight the complex interplay between the biological sample, its preparation protocol and the substrate. Under- 
standing the interaction between biological samples and $\mathrm{Si}_{3} \mathrm{~N}_{4}$ substrate, until now believed to be inert, will help during the realization and utilization of graphene-based liquid cells (Matruglio et al., 2018) with living biological samples, especially providing a better comprehension on the chemical variations observed when these samples are exposed to soft X-rays.

\section{Acknowledgements}

We would like to acknowledge Dr Benedetta Marmiroli (SAXS-DXRL beamlines, TU Gratz, Austria) for kindly providing PVA. We would like to thank Elettra Sincrotrone Trieste for beam time provision (project number 20180110). The authors acknowledge the CERIC-ERIC Consortium for the access to experimental facilities (project number 20182099). This work is part of the scientific activities of the internal CERIC-ERIC research project RENEWALS: gRaphenE for WAter in Life Sciences. Parts of this research were carried out at the FNF, Facility of Nano Fabrication of IOM of Trieste, CNR Italian National Research Council.

\section{Funding information}

The following funding is acknowledged: National Science Centre Poland (grant No. DEC-2013/09/B/NZ4/02539 to Agata Ziomber-Lisiak).

\section{References}

Alizadeh, E., Cloutier, P., Hunting, D. \& Sanche, L. (2011). J. Phys. Chem. B, 115, 4523-4531.

Barth, A. (2007). Biochim. Biophys. Acta, 1767, 1073-1101.

Bedolla, D. E., Mantuano, A., Pickler, A., Mota, C. L., Braz, D., Salata, C., Almeida, C. E., Birarda, G., Vaccari, L., Barroso, R. C. \& Gianoncelli, A. (2018). J. Synchrotron Rad. 25, 848-856.

Beetz, T. \& Jacobsen, C. (2002). Knowl. Creat. Diffus. Util. 10, 280283.

Beetz, T. \& Jacobsen, C. (2003). J. Synchrotron Rad. 10, 280-283.

Bernhardt, M., Priebe, M., Osterhoff, M., Wollnik, C., Diaz, A., Salditt, T. \& Rehfeldt, F. (2016). Biophys. J. 110, 680-690.

Bradshaw, K. \& Smith, M. (2008). Contin. Educ. Anaesth. Crit. Care Pain, 8, 129-133.

Chellan, P. \& Sadler, P. J. (2015). Philos. Trans. R. Soc. A, 373, 20140182.

Collingwood, J. F. \& Adams, F. (2017). At. Spectrosc. 130, 101-118.

Duke, E. M. H., Razi, M., Weston, A., Guttmann, P., Werner, S., Henzler, K., Schneider, G., Tooze, S. A. \& Collinson, L. M. (2014). Ultramicroscopy, 143, 77-87.

Gianoncelli, A., Kaulich, B., Alberti, R., Klatka, T., Longoni, A., de Marco, A., Marcello, A. \& Kiskinova, M. (2009). Nucl. Instrum. Methods Phys. Res. A, 608, 195-198.

Gianoncelli, A., Kourousias, G., Merolle, L., Altissimo, M. \& Bianco, A. (2016). J. Synchrotron Rad. 23, 1526-1537.

Gianoncelli, A., Vaccari, L., Kourousias, G., Cassese, D., Bedolla, D. E., Kenig, S., Storici, P., Lazzarino, M. \& Kiskinova, M. (2015). Sci. Rep. 5, 10250.

Hare, D. J., New, E. J., de Jonge, M. D. \& McColl, G. (2015). Chem. Soc. Rev. 44, 5941-5958.

Hubbell, J. H. \& Seltzer, S. M. (2004). NIST Standard Reference Database 126. National Institute of Standards and Technology, Gaithersburg, MD, USA.

Hunter, J. D. (2007). Comput. Sci. Eng. 9, 99-104.

Jellinger, K. A. (2010). J. Cell. Mol. Med. 14, 457-487.
Johnson, P. S., Cook, P. L., Liu, X., Yang, W., Bai, Y., Abbott, N. L. \& Himpsel, F. J. (2011). J. Chem. Phys. 135, 044702.

Jones, M. W. M., Hare, D. J., James, S. A., de Jonge, M. D. \& McColl, G. (2017). Anal. Chem. 89, 12168-12175.

Jones, M. W. M., Kopittke, P. M., Casey, L., Reinhardt, J., Blamey, F. P. C. \& van der Ent, A. (2020). Ann. Bot. 125, 599-610.

Kirkland, A., Sarlo, G. \& Holton, K. (2018). Nutrients, 10, 730.

Kosior, E., Bohic, S., Suhonen, H., Ortega, R., Devès, G., Carmona, A., Marchi, F., Guillet, J. F. \& Cloetens, P. (2012a). J. Struct. Biol. 177, 239-247.

Kosior, E., Cloetens, P., Devès, G., Ortega, R. \& Bohic, S. (2012b). Appl. Phys. Lett. 101, 263102.

Launer, P. J. \& Arkles, B. (2013). Silicon Compounds: Silanes and Silicones, 3rd ed., pp. 175-178. Morrisville: Gelest.

Leccia, E., Gourrier, A., Doucet, J. \& Briki, F. (2010). J. Struct. Biol. 170, 69-75.

Le Gros, M. A., Clowney, E. J., Magklara, A., Yen, A., MarkenscoffPapadimitriou, E., Colquitt, B., Myllys, M., Kellis, M., Lomvardas, S. \& Larabell, C. A. (2016). Cell. Rep. 17, 2125-2136.

Lombi, E., de Jonge, M. D., Donner, E., Kopittke, P. M., Howard, D. L., Kirkham, R., Ryan, C. G. \& Paterson, D. (2011). PLoS One, 6, e20626.

Lupi, S., Nucara, A., Perucchi, A., Calvani, P., Ortolani, M., Quaroni, L. \& Kiskinova, M. (2007). J. Opt. Soc. Am. B, 24, 959.

Matruglio, A., Zucchiatti, P., Birarda, G., Marmiroli, B., D'Amico, F., Kocabas, C., Kiskinova, M. \& Vaccari, L. (2018). J. Instrum. 13, C05016.

Poitry-Yamate, C., Gianoncelli, A., Kourousias, G., Kaulich, B., Lepore, M., Gruetter, R. \& Kiskinova, M. (2013). J. Phys. Conf. Ser. 463, 012003.

Pushie, M. J., Kelly, M. E. \& Hackett, M. J. (2018). Analyst, 143, 37613774.

Ravelli, R. B. \& McSweeney, S. M. (2000). Structure, 8, 315-328.

Reisz, J. A., Bansal, N., Qian, J., Zhao, W. \& Furdui, C. M. (2014). Antioxid. Redox Signal. 21, 260-292.

Saeed, A., Raouf, G. A., Nafee, S. S., Shaheen, S. A. \& Al-Hadeethi, Y. (2015). PLoS One, 10, e0139854.

Shahidi, F. \& Zhong, Y. (2010). Chem. Soc. Rev. 39, 4067.

Stitt, D. M., Kastyak-Ibrahim, M. Z., Liao, C. R., Morrison, J., Albensi, B. C. \& Gough, K. M. (2012). Vib. Spectrosc. 60, 16-22.

Stryahilev, D., Diehl, F. \& Schröder, B. (2000). J. Non-Cryst. Solids, 266-269, 166-170.

Surowka, A. D., Birarda, G., Szczerbowska-Boruchowska, M., Cestelli-Guidi, M., Ziomber-Lisiak, A. \& Vaccari, L. (2020). Anal. Chim. Acta, 1103, 143-155.

Surowka, A., Ziomber, A., Czyzycki, M., Gianoncelli, A., Bedolla, D., Birarda, G., Kasper, K., Szczerbowska-Boruchowska, M. \& Vaccari, L. (2019). Brain Stimul. 12, 434-435.

Surowka, A. D., Ziomber, A., Czyzycki, M., Migliori, A., Kasper, K. \& Szczerbowska-Boruchowska, M. (2018). Spectrochim. Acta A Mol. Biomol. Spectrosc. 195, 199-209.

Teramoto, T., Azai, C., Terauchi, K., Yoshimura, M. \& Ohta, T. (2018). Plant Physiol. 177, 52-61.

Tzvetkov, G., späth, A. \& Fink, R. H. (2014). Radiat. Phys. Chem. 103, 84-88.

Vallat, R. (2018). J. Open Source Softw. 3, 1026.

Walt, S. van der, Colbert, S. C. \& Varoquaux, G. (2011). Comput. Sci. Eng. 13, 22-30.

Weinhausen, B., Saldanha, O., Wilke, R. N., Dammann, C., Priebe, M., Burghammer, M., Sprung, M. \& Köster, S. (2014). Phys. Rev. Lett. 112, 088102.

Williams, S., Zhang, X., Jacobsen, C., Kirz, J., Lindaas, S., Hof, J. \& Lamm, S. S. (1993). J. Microsc. 170, 155-165.

Ziomber, A., Rokita, E., Kaszuba-Zwoinska, J., Romańska, I., Michaluk, J. \& Antkiewicz-Michaluk, L. (2018). Front. Behav. Neurosci. 11, 262.

Zubavichus, Y., Fuchs, O., Weinhardt, L., Heske, C., Umbach, E., Denlinger, J. D. \& Grunze, M. (2004). Radiat. Res. 161, 346-358. 